\title{
AOR
}

Selected Papers of \#AoIR2019:

The $20^{\text {th }}$ Annual Conference of the Association of Internet Researchers Brisbane, Australia / 2-5 October 2019

\section{PANEL: PLATFORM PEDAGOGIES: LEARNING, AUTHORISING AND VALIDATING TRUST IN EDUCATION}

\author{
Julian Sefton-Green \\ Deakin University \\ Jessica Zacher Pandya \\ California State University \\ Natalie Ann Hendry \\ Deakin University \\ Luci Pangrazio \\ Deakin University
}

\section{INTRODUCTORY STATEMENT}

In recent years, the concept of a platform has gained traction as a way of explaining new kinds of economic, social and civic structure. Originally used to describe a specific interface or website, the idea of a platform has come to stand for the ways that digital services and online participation operate through an integrated array of back-end services and analytics as well as a series of user-facing affordances and interactions across devices/screens that are platform agnostic. The platform thus brings together how an individual at a micro level might, for example, make a purchase, communicate with others, post an opinion, utilise a service and so on, with the socio-technical infrastructure which allows the state and commercial entities that run such platforms to monitor (surveil), harvest, and monetise the aggregated value of such data-driven interactions.

Whilst most of the literature focuses on the emergence of transnational platforms mainly based in the US (Google/Alphabet, Amazon, Facebook et cetera), scholarship has also examined the rise of China's social credit system (Liang, Das, Kostyuk \& Hussain, 2018) or indeed the ways that platforms are now monopolising hitherto discrete market sectors (like Pearsons in Education or Steam/Valve in gaming). 
This panel investigates the pedagogic dimension of these platforms thus drawing on older theoretical traditions that use pedagogy as a way of describing and explaining the relationships between individual and society, agency and structure (paper 1). We want to explore what it means to conceive of the relationship between people and their platforms as a pedagogic relationship; and how such conceptualisations might advance study of platforms in general (paper 4). Additionally, using the term pedagogy in its more specifically educational sense the panel will explore the relationship between learning, schooling and education systems (at different levels) as they are now moving into and across emerging platforms (papers 2 and 3); thus, advancing scholarship about the uses of platforms in Education in general.

Platforms, we argue, standardise and seek to offer a relationship of trust over time with their "citizens". Platforms working with families, schools or in higher education feed off the authority and trust that pertains between citizens and these institutions. However, the platformisation of education (van Dijck, Poell \& de Waal, 2018) may contain other kinds of risks for students and their families, thereby introducing the need for new forms of validation. By thinking about activities in and across a series of platforms in terms of pedagogic relationships, where trust is placed in authority, the panel will explore the mechanisms by which digital interactions take forms of social trust and yet expose people to forms of dataveillance beyond ways that any membership or participation suggests in its initial contract. These digital interactions may compel pedagogies that evoke discomfort, loss and constraint as they 'manage student experience' rather than invite learning relationships.

The panel comprises early mid-career and senior scholars who have come together through an international collaboration working on platform pedagogies. Together they have backgrounds in cultural studies, media communication, initial teacher education and preparation, critical data science and learning sciences. A mixture of theoretical and empirical studies enable the panel to address fully ways in which pedagogy might be said to be coming platformized even as it explores the platformization of education.

\section{References}

Liang, F., Das, V., Kostyuk, N., \& Hussain, M. M. (2018). Constructing a Data-Driven Society: China's Social Credit System as a State Surveillance Infrastructure. Policy and Internet, 10(4).

van Dijck, J., Poell, T., \& de Waal, M. (2018). The Platform Society. Oxford, UK: Oxford University Press. 


\title{
CONCEPTUALISING OUR RELATIONSHIP WITH ONLINE/DIGITAL PLATFORMS IN TERMS OF PEDAGOGY
}

\author{
Julian Sefton-Green \\ School of Education, Deakin University, Australia
}

\section{Issue and research questions}

This paper attempts to theorise user interactions, activity and relationships with digital platforms in terms of pedagogy; and to consider the political social and educational implications. The concept of pedagogy tends to occupy an intermediate position in explanations for the operation of power (Parker, 2000). However, in the context of discussion about how platform interactions recalibrate understandings of individual agency and structural determinism - especially in relationship to datafication and surveillance (van Dijck, 2014) - pedagogy offers a nuanced explanation to account for perspectives of both interaction and control. Pedagogy additionally provides a vocabulary and a model of how control is exerted/negotiated to explain both the learning of trust (e.g. Murphy-Graham, \& Lample, 2014) and the ways that trust (or the deferral of risk) is built into the operation of platforms.

\section{Critical Framework}

The use of the term platform has grown in recent years to suggest a closed, programmable, proprietary online site that can be accessed across many different devices (from desktops to mobile phones) and which builds relationships, interactions and data about those interactions within its system( Gillespie, 2010; Plantin, Lagoze, Edwards, \& Sandvig, 2018). Recent scholarship suggests that these platforms are manifestations of contemporary forms of capitalism (Srnicek, 2016; Zuboff, 2019). Yet these approaches to the study of platforms conceptualise the platform-user relationship significantly in terms of structural determinism focusing on how the asymmetric/unequal relationship between the platform and the individual effectively interpellates people through datafication with constraining consequences. Indeed, the harvesting of seemingly unconscious (or unintentional) data behaviours and their repurposing as commodified surplus (Zuboff, 2019) seems to represent a form of "mind control" and manipulation that bedevilled earlier interpretations of ideology as an explanation for power for the last 150 years. Whilst there are exceptions to research investigating the possibilities of resisting or negotiating how platforms frame use and interaction (Bucher, 2018), to date these have not been imagined as a form of pedagogic power.

As a theory of power, pedagogy (the structural relationship surrounding teaching and learning) shows how what actually happens as people "learn" the behaviours and actions that reflect dominant ideological positions. Bernstein (Bernstein, 1973;1990, 2000) showed that it is the processes of pedagocization (how human activity becomes framed as authorized school knowledge) with its control over forms of knowledge and language that validate unequal power relations especially that of trust in authority. Understanding the interplay of pedagogic authority with its attention to the ways that knowledge is framed and classified and what Bourdieu called "symbolic 
violence"(Bourdieu \& Passeron, 1990)points not just to the processes by which people become incorporated in their contemporary social order but the huge range of affordances that shape, support and prohibit such modes of subjectification. Finally, the neo-institutionalist concern with world schooling(Baker, 2014)shows how the wider success of pedagocization into hitherto unschooled domains (Sefton-Green \& Erstad, 2018)offers a template to make sense of how pedagogic regimes work.

\section{Relevance to wider conference themes}

How then might theories of pedagogy help make sense of the power of platforms? How can a theory of pedagogy help us disentangle questions of trust, control, agency and power? I suggest two avenues of analysis. First, a theory of pedagogy directs attention to the processes by which users learn behaviours, language, modes of interaction, meanings and indeed subscribe to the risks, benefits, comforts and values of the platform. Following ethnographies of algorithmic identities (Bucher, 2018), Facebook (Miller et al., 2016), or affinity learning (Ito et al., 2018) I suggest it is generative to look at forms of participation and interaction as modes of learning. This perspective not only gives insight into the pleasures and rewards of belonging and participating on platforms but also helps us understand the amount of work making sense of how to participate, how to behave and how to engage with each other across platforms. This avenue of enquiry also includes ideas of thinking what is at stake as people progress through and across different platforms at different stages of their lives both suggesting some notion of stepped progression and core "platform skills" at the same time as the platforms themselves are seeking to "Balkanize" and increasingly control their citizens lives.

The second avenue of enquiry examines how the spread of platforms and their successful incorporation of compliant subjects should be seen in terms of the wider spread of pedagocization (Sefton-Green \& Erstad, 2018) into everyday life. This perspective helps us understand how forms of digital control and surveillance not only command absolute authority (a key theme in Bourdieu and Bernstein) but mitigate trust through forms of depersonalized algorithmic abstraction. Understanding the spread of platforms and the compliant behaviours they enact can profitably be understood as the apotheosis of the "totally pedagogicized society" (Tyler, 2004) as much as contemporary political appeal is framed in terms of surveillant control(Zuboff, 2019). Above all, pedagogy offers spaces for political intervention, reform and change promising at least some semblance of control by people over these technologies, possibly offering more trust in forms of politics we now feel we have lost.

\section{References}

Baker, D. (2014). The Schooled Society: The Educational Transformation of Global Culture. Stanford: Stanford University Press.

Bernstein, B. (1973). Class, Codes and Control: Theoretical Studies Towards a Sociology of Language. London: HarperCollins.

Bernstein, B. (1990). Class, Codes and Control: The Structuring of Pedagogic Discourse v. 4 (Class, Codes and Control, Vol 4). Routledge. 
Bernstein, B. (2000). Pedagogy, Symbolic Control and Identity. London: Rowman \& Littlefield Publishers.

Bourdieu, P., \& Passeron, J.-C. (1990). Reproduction in Education, Society and Culture. London: Sage.

Bucher, T. (2018). If, Then: Algorithmic Power and Politics. New York: Oxford University Press.

Gillespie, T. (2010). The politics of 'platforms. New Media and Society, 12(3), 347-364.

Ito, M., Martin, C., Pfister, R. C., Rafalow, M. H., Salen, K., \& Wortman, A. (2018). Affinity Online: How Connection and Shared Interest Fuel Learning (Connected Youth and Digital Futures)., 228.

Miller, D., Costa, E., Haynes, N., McDonald, T., Nicolescu, R., Sinanan, J. et al. (2016). How the World Changed Social Media (Why We Post). UCL Press.

Murphy-Graham, E., Lample, J., Learning to trust: Examining the connections between trust and capabilities friendly pedagogy through case studies from Honduras and Uganda. Int. J. Educ. Dev. (2014), http://dx.doi.org/10.1016/ j.ijedudev.2014.01.001.

Parker, J. (2000). Structuration Milton Keynes: Open University Press.

Plantin, J. C., Lagoze, C., Edwards, P., \& Sandvig, C. (2018). Infrastructure studies meet platform studies in the age of Google and Facebook. New Media \& Society, 20(1), 293-310.

Sefton-Green, J., \& Erstad, O. (2018). Learning Beyond the School: International Perspectives on the Schooled Society London:. Routledge.

Srnicek, N. (2016). Platform Capitalism. Polity Press.

Tyler, W. (2004). Silent, invisible, total: Pedagogic discourse and the age of information. In J. Muller, B. Davies, \& A. Morais (Eds.), Reading Bernstein, Researching Bernstein (pp. 20-28). London: Routledge.

van Dijck, J. (2014). Datafication, dataism and dataveillance: Big Data between scientific paradigm and ideology. Surveillance \& Society, 12(2), 197-208.

Zuboff, P. S. (2019). The Age of Surveillance Capitalism: The Fight for a Human Future at the New Frontier of Power (Main ed.). Profile Books. 


\section{TEACHERS' USE OF APPS AND PLATFORMS: AN EMPIRICAL STUDY}

Jessica Zacher Pandya

College of Education, California State University, Long Beach, USA

\section{Issue and research questions}

Research in science and technology studies, anthropology, and increasingly in education is now focusing on the effects of living in a posthuman, cognitive capitalist world in which techno-rational policy decisions are made with increasing reliance on Algenerated data about student and teacher performance (Lawn, 2013; Means, 2018; Peters \& Bulut, 2011). One visible but under-examined phenomenon in this area is the use of apps and platforms by teachers in $\mathrm{k}-12$ classrooms. Teachers can monitor classroom behaviour, collect information about student progress, and share information with parents with apps like Class Dojo, Active Classroom, and ParentSquare, as well as via larger platforms like Beachboard. Education researchers and academics who prepare future teachers have recently begun to examine the ways these platforms may be shaping new methods of classroom behaviour management and changing the way teachers and parents communicate.

For instance, one popular app, Class Dojo, allows teachers to mass-message all parents in the class, or message parents individually. Parents in turn can message the teacher (though not other parents). Teachers can include photos and videos in their messages to show school activities or children's work. Teachers frequently use it as a behaviour management tool in lieu of more old-fashioned methods, and much of the emerging work on Class Dojo and similar apps focuses on their behaviour management functions. Some of this research examines the efficacy of the app for behaviour management vs. paper and pencil methods (cf. Krach, McReery, \& Rimel, 2017). Other research is beginning to focus on the extent to which the app's underlying socialemotional focus "reinforces and rewards students for behaviours that are becoming the basis for emerging school accountability systems" (Williamson, 2017, p. 3441). What we do not yet know is how teachers are engaging with these apps in practice, and what theories teachers hold about app use.

I have examined teachers' use of apps and platforms of all varieties because of their proliferation. I have asked three kinds of questions: 1) Practice: What do teachers use apps and platforms for? How regularly do they engage with the apps in and out of school? How are their app use practices reshaping their behaviour management and/or home-school communication practices? 2) Conceptual: What are teachers' conceptions of the apps themselves? What is their understanding of where the apps come from, why they are using them, why they chose one app over another? And 3) Data-related: To what extent do teachers think about the data their practices are generating? Do they understand who owns the data, and what rights they, their students, and their students' parent have vis a vis data ownership, sharing, and privacy? Do they attend to any of the privacy settings of the apps they use? 


\section{Methodological framework}

This project uses qualitative interview methods to investigate teachers' self-reported practices and perceptions (future ethnographic work will address classroom practice). I conducted over 30 long form, semi-structured interviews with teachers from kindergarten to 8th grade (middle school in the US), using a snowball sampling procedure (Weiss, 1994). Taking a grounded theory approach to both initial and subsequent analysis and theory-building (Glaser \& Strauss, 1999), I engaged in a process of simultaneous data collection and analysis, pursuing emergent themes (described below) and, eventually, inductively constructing categories (Charmaz \& Belgrave, 2013) of practice, teacher awareness, and teacher data use that I describe below.

\section{Findings and relevance to wider conference themes}

My interview and research questions focused on practice, conceptual knowledge, and understandings of data. Findings from analysis thus far suggest three main findings, with many implications for educator preparation and classroom and home-school life. The first of three main themes was utility: teacher participants focused on the ways they used apps to enhance their existing practices, from behaviour management to sending out flyers and information to parents. Most teachers saw the apps they used as easily accessible tools in a self-fulfilling manner, because teachers only repeatedly or regularly used apps that were easy for them to use. Many reported using apps initially for one purpose and learning additional uses of an app over time, but the vast majority only consistently used apps that were easily adoptable into their daily teaching practices. They learned about the apps from a range of sources: professional development in and out of their school sites, as well as referrals from colleagues, friends, and family members. They judged the utility of each app for how it made their work lives more streamlined.

The second main finding is that teachers did have somewhat vague concerns with privacy and data ownership, but those were mitigated in their minds by school districts' vetting of apps. That is, they understood that there are implications to, for instance, sharing photos of groups of children with all parents in a class, but they believed their use of those photos was covered in parent permissions (given to the app itself) and by the official nod given such apps by their school districts. For example, few teachers had read the user agreements parents sign, and most believed the ways they shared images was harmless and, indeed, beneficial to students and parents. Teachers also seemed to believe that, since they had put their trust in their school district about privacy and safety, parents should do the same in turn (putting their trust in teachers, who had invited them to use the apps).

The third finding is about teachers' framings of access and inclusion. In the cases of apps that connected teachers with families or parents, teachers tended to see parents who used the apps as good at parent participation, and, conversely, those who did not choose to use the apps as uninterested or uninvolved with their child's schooling. There was little mention of access issues like having a smartphone or being able to use the app in languages other than English (teachers generally thought all parents had 
smartphones at the least, and they also seemed to think that apps would work in multiple languages). There was also little consideration of parents' technological skill level, including either the sense that parents were put off by the technology itself, that they might opt out because of insufficient data security. These findings speak directly to the conference theme of trust at a granular level, in the practices of end users, and should offer conference attendees insight into the role of trust in teachers' and parents' practices.

\section{References}

Glaser, A. \& Strauss, A. (1999). The Discovery of grounded theory: Strategies for qualitative research (2nd Ed.). New York, NY: Transaction Publishers.

Krach, S. K., McCreery, M. P., \& Rimel, H. (2017). Examining teachers' behavioral management charts: A comparison of Class Dojo and paper-pencil methods. Contemporary School Psychology.

Lawn M (Ed.) (2013). The Rise of Data in Education Systems: Collection, Visualization and Use. Oxford: Symposium.

Means, A. (2018). Platform learning and on-demand labor: sociotechnical projections on the future of education and work. Learning, Media and Technology, 43 (3), 326-338. Peters, M. A., \& Bulut, E. (2011). Cognitive Capitalism, Education and Digital Labor. Bern, Switzerland: Peter Lang US.

Weiss, R. (1994). Learning from strangers: The art and method of qualitative interview studies. New York: The Free Press.

Williamson, B. (2017). Decoding ClassDojo: Psycho-policy, social-emotional learning and persuasive educational technologies, Learning, Media and Technology, 42:4, 440453, DOI: $10.1080 / 17439884.2017 .1278020$ 


\title{
TRUSTING THE EXPERTISE OF THE LEARNING MANAGEMENT SYSTEM
}

\author{
Natalie Hendry \\ School of Education, Deakin University
}

\section{Issue and research questions}

Higher education institutions in Australia have embraced a range of commercial education products, alongside in-house learning platforms, to provide a 'digital learning environment' for students and staff. These include customised or integrated products such as Moodle, Blackboard, Canvas, Sakai and Brightspace, as well as Google or Microsoft suites to manage online seminars or file sharing. In this way, products like Learning Management Systems (LMS) may be examples themselves of digital platforms or embedded as sites or tools within more extensive institutional platforms that combine marketing, timetabling, finance, student management and operational functions.

This paper considers pedagogy as a practice (or practices) in closed, cloud-based platforms for learning and teaching - or Learning Management Systems - at higher education institutions. These LMS are expanding at scale and speed in higher education (Coopman, 2009), and institutions in Australia are amassing learning design teams to develop, design, manage and measure LMS use by staff and students alike.

This paper outlines taken-for-granted pedagogical norms that emerge from LMS teaching. I argue that LMS coerce constraining pedagogies from educators. These pedagogies shift the expertise of teachers working (both in the classroom and/or in digital encounters), with students, to the learning design expertise of teams of multidisciplinary developers and designers and the learning platform structure itself.

This paper does not posit on-campus teaching against LMS teaching (and thus does not reiterate earlier arguments regarding distance education). Rather, I articulate the pedagogical practices that LMS teaching impels, my discomfort with how they constrain teaching and learning, and what other pedagogical traditions may offer to reimagine future teaching beyond the LMS. I consider this in light of increasing obligations towards institutional measures of 'student engagement' and the international higher educational market.

\section{Critical framework}

As an emerging research project, this paper draws on my own and colleagues' reflections from engaging as a community of practice (Wenger, 1998) to explore platform pedagogies. My thinking about LMS is marked by sadness and loss; teaching in an LMS marks a loss of uncertainty, flexibility, experimentation and relationship that is centred in my teaching practice, mostly in the context of initial teacher (or pre-service teacher) education programs. My practice is enriched by feminist, community and critical pedagogy theories of learning and teaching and my training in community health 
education first as a peer educator, then as a workshop facilitator and trainer schooled in feminist workshop methods.

Here, I outline three of the pedagogical implications of LMS that this emerging project has encountered: the structures of LMS, surveillance and the instrumentalization of collaboration.

First, the technological and interface structures of LMS constrain pedagogical decisions for both teachers and students. As Coopman (2009) stresses, 'the ways in which course materials are presented and accessed - and who gets to present what and when form a key component in the online classroom.' The LMS replicates itself each semester, each year. Content is digitally transported into a new interface, fresh with a new layout for the new year. The replication of content frames teaching as 'updating' content, regardless of changing student contexts. This homogenises learning and redirects teaching towards content delivery.

LMS structure learning as a practice of management even as they conceal this relationship in favour of discourses of digital collaboration and anywhere-learning. The learning experience is managed through institutional branding and templates and is guided by instruction that borrows theory from learning design approaches that ignore the rich histories of many different pedagogical traditions.

Second, professional teams of digital learning staff measure and monitor the success of learning design activities through the surveillance of both student and teacher 'engagement'. Engagement, for learners, is enacted at the level of visible data: the panels of 'participation metrics' that announce participation via the quantifiable minutes spent on each platform, page, tool or file. The capacity for surveillance relies on the closed nature of the LMS system. Both student and teacher commitment to learning is quantified by these metrics and meeting 'minimum' standards for LMS teaching e.g. introductory videos, prompt replies to discussion board questions.

Each closed platform operates as another university campus - some naming and coding their online LMS platform as a campus - that restricts outsiders or community engagement through the management of accounts, passwords and server restrictions. This sits at odds with the openness of the internet, 'its most radical and pedagogically viable feature' (Morris and Stommel, 2015, p. 168). The closed system also regulates and shapes material lives of its teacher users. In one Australian institution, for example, casual lecturers and tutors may not work across multiple institutions as it jeopardises the university's ownership of intellectual property given the ease of downloading 'entire courses'. (Of course, this has explicit consequences for those academics working in an increasingly insecure and casualised job market.)

Finally, my third illustration attends to practices of 'collaboration' on LMS, where collaboration is instrumentalised as 'posting' and 'responding' to content (and perhaps more importantly, lurking and 'listening' to draw on Crawford's [2009] concept). This occurs at the site of the discussion board or forum which becomes championed as a symbol of connection and social participation. At the level of pedagogical practice - 
what we actually do as educators and why - the promises of LMS and its discussion boards fall short.

\section{Relevance to wider conference themes}

How then does pedagogical expertise emerge through cloud-based platforms for teaching and learning? Or rather, who is the expert teacher?

These three pedagogical implications of LMS, and no doubt others, make expertise invisible as pedagogical decisions are dispersed through digital teams and the LMS' structure and affordances.

The expertise shifts from teachers and students (who rarely contribute to the structure or process of the LMS, beyond evaluation data at the end of courses) to the LMS and the teams that support it's taken-for-granted roll out and ongoing upgrades. At the same time, these decisions may be obliged by LMS teams and the structure of the LMS, but equally the pedagogical implications of LMS are embedded in institutional governance. This includes learning and teaching committees and leadership teams, policies related to teaching, assessment and enrolment, and the broader global context of competitive digital learning markets.

In this way, trust in LMS teaching is not a practice for teachers or students. How then can we move to critique the 'expertise' and pedagogical practices of LMS? What is beyond the LMS? How might other pedagogical traditions and practices - digital or not - enrich and inspire this thinking?

\section{References}

Coopman, S.J. (2009). A critical examination of Blackboard's e-learning environment. First Monday. 14(6). https://firstmonday.org/ojs/index.php/fm/article/view/2434

Crawford, K. (2009). Following you: Disciplines of listening in social media. Continuum, 23(4), 525-535. https://doi.org/10.1080/10304310903003270

Morris, S.M., \& Stommel, J. (2015). The course as container: Distribute learning and the MOOC. In P.C. Layne \& P. Lake (eds.), Global Innovation of Teaching and Learning in Higher Education

Wenger, E. (1998). Communities of practice: Learning, meaning, and identity. Cambridge: Cambridge University Press. 


\section{PEDAGOGIES FOR PLATFORM PARTICIPATION: EXPLORING THE PRODUCTIVE TENSION BETWEEN TRUST AND DISTRUST}

Luci Pangrazio,

School of Education, Deakin University, Australia

\section{Issue and research questions}

In this paper I report on an educational project that sought to develop young people's critical understandings of platform mechanisms (van Dijck et al., 2018). The pedagogical approach drew on the productive tension between trust and distrust (Benamati et al., 2010) to support young people to evaluate critically how platform mechanisms, such as datafication, personalisation and commodification, shape their interactions and participation on the platform.

Social media platforms are integral to maintaining and extending social relationships for most young people today. They provide opportunities to experiment with identities; discover information; learn; engage with civic and political life; and generally, make sense of growing up (Lincoln \& Robards, 2017). For many young people social media are no longer something they 'use', but rather a fabric woven into all aspects of day-today life.

While it is important for young people to trust the platform in order to take advantage of the benefits on offer, blind trust can lead to increased risk of media manipulation, profiling and heightened surveillance. The educational program trialled in this project sought to prevent these risks by increasing the student participants' technological knowledge of how platforms operate.

Platform mechanisms are complex. The interface covers over much of the complexity and many of the mechanisms are 'black-boxed' or hidden from view, meaning educational programs need to be tailored specifically to the structure of platforms. Drawing on platform studies (Langlois \& Elmer, 2013; van Dijck, 2013; van Dijck et al., 2018) and digital literacies (Avila \& Pandya, 2013; Pangrazio, 2016) for key concepts and content, the educational program sought to exploit the productive tension between trust and distrust to develop young people's understandings of platform mechanisms, while also acknowledging the prosocial opportunities they offer.

\section{Methodological framework}

The aim of this study was to investigate the critical understandings of platform mechanisms teenagers have and how they might be developed in relation to their platformed identities. Drawing on the findings of a larger one-year program involving 84 young people (aged 12-14 years) and four teachers, the paper addresses the following questions: 
1. What social media platforms do young people use?

2. What do young people know about platform mechanisms?

3. How effective was the program in developing young people's understanding of platform mechanisms?

The evaluation required a methodology that was sensitive to how the program was delivered and received in school contexts. To achieve this balance the evaluation design adopted a mixed method approach, involving pre- and post-program surveys, post-program focus-group discussions and observations of the program in action. Interviews with participating teachers were also conducted. This yielded fine-grained insights into the experiences, perceptions and attitudinal changes of participating students and teachers through qualitative data gathering approaches, as well as broad sweep data on how participants' knowledge and understanding had changed.

\section{Findings}

The pre-program survey revealed that 67 out of the 84 young people had social media accounts, with YouTube, Snapchat and Instagram by far the most popular platforms. While the young people had heard of many terms associated with platforms (i.e. algorithms, data metrics, personalisation), most were unsure about what these meant and their function.

None of the teachers and students had participated in a program like this before and all could see the need to understand how platform mechanisms shape digital participation. Indeed, the findings accord with concerns of scholars (Mihailids, 2018; boyd, 2017) who argue that current digital and media literacies are not addressing the technological features of platforms and how this shapes user participation.

The program was broken up into three main sections: the first encouraged young people to critically reflect on platform practices and identities; the second developed understandings of platform structures and mechanisms, drawing on topical issues to demonstrate concepts (i.e. fake news, data profiling); and the final section supported the student participants in making good decisions for platform participation, particularly in regard to complex issues such as online coercion and content sharing.

Findings indicate that the young people significantly increased their understanding of key concepts, (i.e. echo chamber, algorithms, personalisation, fake news and online coercion) as a result of participating in the program. These would help them to navigate the platform more critically in the future. Fake news and digital identities were considered to be the most valuable topics addressed in the program.

Despite increased critical awareness of platform mechanisms, the findings indicate the program was limited in initiating more critical platform practices and behaviours. This can be explained in two ways. First, platform practices and behaviours are still strongly influenced by social practices and networks. Second, the consequences of platform mechanisms often remain nascent to users through a process of what Langlois and Elmer (2018) call 'impersonal subjectivation'. These findings suggest a more iterative 
and cumulative approach might have more success; however, this would take much longer than could be achieved in the timeframe of this program.

\section{Relevance to wider conference themes}

Developing knowledge of how platform mechanisms shape content and participation helped student participants to navigate a productive line between trust and distrust of the platform. Given the benefits of platforms for young people's futures, abandoning platform participation is not a realistic solution. Instead a pedagogy that fosters a healthy distrust, while at the same time exploring how platform mechanisms might be exploited to achieve personal needs, is far more productive.

While the findings reveal the overall effectiveness of the program, there were several limitations to the study. First, the evaluation relied on student participants self-reporting their knowledge of key concepts. Second, while the same resource materials were provided to participating teachers, each teacher took a different approach, meaning that concepts and content were scaffolded differently.

The paper concludes with three recommendations for future research into pedagogies of platform participation. First, as platform participation is as much social as technological, programs should include opportunities for young people to collectively reflect upon platform mechanisms. Second, an iterative approach in which key concepts and ideas are revisited in subsequent years will have more success in actually changing behaviour and practices. Finally, subsequent stages of the program might consider helping young people understand the 'new relational politics' (Langlois \& Elmer, 2018) of platforms in the broader digital economy.

\section{References}

Avila, J., \& Pandya, Z. (2013). Critical Digital Literacies as Social Praxis: Intersections and Challenges. New York: Peter Lang Publishing Inc.

boyd, d. (2017). Did media literacy backfire? Data \& Society: Points. Retrieved from https://points.datasociety.net/did-media-literacy-backfire-7418c084d88d

Langlois, G., \& Elmer, G. (2013). The research politics of social media platforms. Culture Machine, 14, 1-17.

Langlois, G., \& Elmer, G. (2018). Impersonal subjectivation from platforms to infrastructures. Media, Culture and Society, 1-18.

doi:oOr.g1/107.171/0771/60314634434731781881188374

Lincoln, S., \& Robards, B. (2017). Editing the project of the self: sustained Facebook use and growing up online. Journal of Youth Studies, 20(4), 518-531.

Mihailidis, P. (2018). Civic media literacies: Re-imagining engagement for civic intentionality. Learning, Media and Technology, 43(2), 152-164. 
Pangrazio, L. (2016). Reconceptualising critical digital literacy. Discourse: Studies in the Cultural Politics of Education, 37(2), 163-174. doi:10.1080/01596306.2014.942836

van Dijck, J. (2013). The Culture of Connectivity: A Critical History of Social Media. New York: Oxford University Press.

van Dijck, J., Poell, T., \& de Waal, M. (2018). The Platform Society. Oxford, UK: Oxford University Press. 